\title{
Elecciones municipales, intervenciones del gobierno $y$ conformación de elencos políticos. Baradero, 1856-1862*
}

\section{Municipal Elections, Government Interventions and the Formation of political groups. Baradero, 1856-1862}

\author{
PABLO A. GONZÁlEZ LOPARDO
}

\section{Resumen}

El presente trabajo reconstruye las formas que asumieron las prácticas electorales municipales y su articulación entre distintos niveles de gobierno en el marco de la instalación de las municipalidades de campaña, tomando el caso de la Municipalidad de Baradero, entre 1856 y 1862, a fin de ponderar la tensión de ser considerados como órganos de autogobierno local o como órganos administrativos del Estado de Buenos Aires en el territorio. Consideramos que el proceso de municipalización abierto luego de la separación de Buenos Aires de la Confederación Argentina permitió la asunción de potestades locales y la incorporación de nuevos actores políticos.

\section{Palabras clave}

Estado de Buenos Aires; Elecciones; Campaña Bonaerense; Política Municipal.

\begin{abstract}
This work reconstructs the forms assumed by municipal electoral practices and their articulation between different levels of government in the context of the installation of campaign municipalities. It takes the case of the Municipality of Baradero between 1856 and 1862 , in order to ponder the tension of being considered as bodies of local self-government or as administrative organs of the State of Buenos Aires in the territory. We consider that the process of municipalization opened after the separation of Buenos Aires from the Argentine Confederation allowed the assumption of local powers and the incorporation of new political actors.
\end{abstract}

\section{Keywords}

State of Buenos Aires; Elections; Buenos Aires Campaign; Municipal Policy.

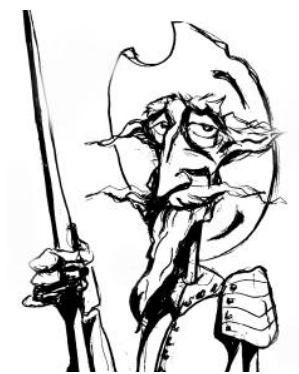

Recibido con pedido de publicación el 7 de abril de 2021

Aceptado para su publicación el 20 de julio de 2021

Versión definitiva recibida el 2 de septiembre de 2021

https://doi.org/10.35305/prohistoria.vi36.1520

Pablo A. González Lopardo, Universidad Nacional de Mar del Plata, Mar del Plata, Argentina; e-mail: pagonzalezlopardo@gmail.com

\footnotetext{
* Agradezco los comentarios de los evaluadores anónimos de la revista.

Esta obra se publica bajo licencia Creative Commons. Atribución-NoComercial-CompartirIgual 4.0 Internacional

González Lopardo, P. Elecciones municipales, intervenciones del gobierno y conformación de elencos políticos. Baradero, 1856-1862. Prohistoria, Año XXIV, 36, dic. 2021, 1-27.
} 


\section{Introducción}

Las formas de gobierno locales han sido, en Hispanoamérica al menos, un terreno de difícil caracterización historiográfica en tanto constituyen fenómenos políticos atravesados por una gran cantidad de aristas y matices, desde los cuales se ha intentado problematizar la temática (Canedo, 2016). A esto se le suma la dificultad que implican las especificidades propias de la conformación histórica de cada caso. Por este motivo, resulta pertinente la perspectiva de Federica Morelli (2007) al destacar la doble y ambigua naturaleza del municipio de fines de siglos XVIII y del siglo XIX, atravesado por la tensión de ser considerado como representante de los intereses locales frente al poder central y de representante del poder central en el territorio, que acompañó el proceso más general de construcción de los Estados nacionales.

El presente trabajo se inscribe en el marco de esta problemática y procura dar cuenta del proceso político que, a mediados del siglo XIX, generó la posibilidad de elegir representantes municipales y modificó la práctica de confeccionar ternas para el cargo de juez de paz. En tanto que la instalación de las municipalidades habilitó, por un lado, la elección mediante el voto popular de autoridades locales y, por otro, facultó a los municipales a designar la terna de juez de paz, resignificando una práctica de larga data (Garavaglia, 1997; Gelman, 2000), analizaremos esta particularidad del espacio bonaerense a partir del caso de la Municipalidad de Baradero, en el período comprendido desde su instalación en febrero de 1856 hasta 1862 cuando Buenos Aires se incorporó como provincia a la República Argentina.

Pretendemos avanzar en el análisis del proceso de municipalización de la campaña iniciado a mediados del siglo XIX en el territorio del Estado de Buenos Aires separado de la Confederación Argentina, que no ha sido suficientemente estudiado para el caso de los pueblos rurales y que implicó la posibilidad asumir potestades que fueron generando nuevas jurisdicciones en diversas esferas (electoral, territorial, fiscal, educativa, etc.), así como la incorporación de nuevos actores en su construcción (Canedo, 2019b, 2020). Si bien disponemos de trabajos referentes que han abordado distintos aspectos de los procesos de implementación de las municipalidades (Ternavasio, 1991; Sonzogni y Bonaudo, 1997; Salaberry, 2009), aún no se ha profundizado en las prácticas del sufragio municipal ni en las relaciones con instancias estatales superiores.

Se trata de abordar el problema de la doble y ambigua naturaleza de los poderes locales a partir de las prácticas electorales de los actores (autoridades, votantes, jueces de paz, municipales), enmarcadas en el proceso de conformación de las municipalidades de la campaña bonaerense. Para ello, proponemos entender estas nuevas instituciones surgidas a mediados del siglo XIX como actores políticos, a fin de evaluar en qué medida se constituyeron como nuevos espacios de participación y competencia política, otorgando un rol 
destacado a los ámbitos locales en su relación con el poder central, continuando el camino del fortalecimiento de los gobiernos municipales al avanzar en el autogobierno y en las potestades que se les asignaron y fueron asumiendo (Canedo, 2019a y 2020; Zubizarreta, 2018; Kozul, 2018).

Trataremos para dar respuesta a algunos interrogantes que servirán de guía de este trabajo, tales como ¿Quiénes conformaron los elencos de gobierno local desde la instalación de la Municipalidad en Baradero?, ¿Cómo accedieron a los cargos municipales?, ¿Qué prácticas y relaciones políticas expresaron las elecciones municipales?, ¿Cuáles fueron los vínculos entablados con las autoridades del gobierno de Buenos Aires? A partir de estas cuestiones se intentará echar luz sobre las formas que asumieron las prácticas electorales municipales y cómo se articuló el diálogo entre poder local y poder central en el marco de la instalación de las municipalidades de campaña, en una coyuntura caracterizada por la conformación del Estado de Buenos Aires como entidad política soberana y por la confrontación política y militar con la Confederación Argentina (Miguez, 2018).

Argumentamos que, en este contexto, el funcionamiento municipal se erigió como un nuevo canal para la práctica política que trascendió el ámbito local y se proyectó a esferas superiores, permitiendo la convergencia de prácticas políticas de antigua data con otras formas más novedosas. En este sentido, nuestra hipótesis radica en que la introducción de mecanismos de representación en el ámbito local a partir de la instalación de las municipalidades constituyó una nueva instancia de articulación entre distintos niveles de poder. Los procesos electorales que analizaremos nos permitirán comprender la construcción de los nuevos ordenamientos políticos municipales.

El caso de Baradero ofrece una variedad de puertas de entrada desde donde abordar la política municipal a fin de problematizar la relación, no siempre armónica ni siempre conflictiva, entre el ejercicio de los poderes locales por un lado y la soberanía del Estado de Buenos Aires en tanto poder central por el otro. Ubicado geográficamente en la zona norte del territorio bonaerense, a orillas del Río Paraná y a unos $150 \mathrm{~km}$ de la ciudad de Buenos Aires, compartía a mediados de siglo con los pueblos de San Pedro y San Nicolás de los Arroyos una importancia política estratégica para el gobierno del Estado de Buenos Aires en tanto se situaba en una zona limítrofe con la Confederación Argentina, lo que terminó por involucrar a su población en las disputas entre ambas entidades políticas. La cercanía a los campos de Cepeda, donde se desarrolló una de las batallas más significativas del período, da cuenta de esta singularidad.

Las fuentes utilizadas son variadas y remiten a un corpus documental aún en construcción, que incorpora actas de sesiones municipales, certificados de escrutinios, correspondencia epistolar, comunicaciones oficiales, censos, 
cuerpos normativos. Se destaca el 'Libro de Acuerdos Municipales entre 1856 y 1862', en tanto constituye un tipo de fuente que no ha sido sistemáticamente analizada. En ella constan las actas de las 166 sesiones, ordinarias y extraordinarias, de la Municipalidad desde su instalación, en lo que constituye un registro detallado de los temas tratados por los municipales, donde se pone de manifiesto su funcionamiento y se pueden identificar prácticas y formas de hacer política municipal.

Presentaremos a continuación una breve caracterización sobre la organización institucional de la campaña bonaerense en el período para luego pasar a analizar la dinámica institucional municipal, la conformación de ternas de jueces de paz y las prácticas electorales municipales abordadas en 3 ejes: conformación del elenco municipal, conflictos políticos y participación electoral. Finalmente propondremos algunas conclusiones.

\section{La organización institucional de la campaña bonaerense a mediados del siglo XIX}

El levantamiento del 11 de septiembre de 1852 constituyó el inicio de una serie de operaciones de la dirigencia porteña que apuntaron a consolidar y reforzar la victoria en el terreno de las armas mediante la construcción y apropiación de diversos símbolos y representaciones, entre las cuales la defensa de la autonomía provincial (en términos políticos y financieros) y el problema de la legitimidad fueron aspectos centrales (Lettieri, 2003: 97-98). Producida la separación de Buenos Aires de la Confederación Argentina, los grupos dirigentes de la ciudad vieron la necesidad de crear consenso político en el ámbito de los pueblos rurales como forma de afianzar su predominio, fundamentalmente luego de derrotado, en junio de 1853, el sitio a Buenos Aires iniciado en diciembre del año anterior por parte de las fuerzas federales de Hilario Lagos. Ello, en tanto que para la élite política porteña la campaña bonaerense quedó asociada al federalismo rosista (Barcos, 2012).

La Constitución del Estado de Buenos Aires, sancionada el 11 de Abril de 1854, legisló sobre el sistema representativo, la división de poderes, las libertades civiles y, en lo que interesa a este trabajo, el establecimiento del régimen municipal en todo el territorio bonaerense, cuyas atribuciones, deberes, formas de elección y administración de recursos serían pautados mediante una ley específica (Art. 170). ${ }^{1}$ Estableció el concepto de la soberanía interior y exterior ejercida por los poderes constituidos, delimitando territorio (Aramburo, 2016). Si bien la Constitución de 1854 llevaba implícita una idea de

${ }^{1}$ Constitución del Estado de Buenos Aires, 1854, Recopilación de leyes y decretos promulgados en Buenos Aires desde enero de 1841 hasta la fecha (Recopilación), Buenos Aires, Imprenta de Mayo, 1858, pp. 679-680. 
transitoriedad, la élite política porteña consideraba a Buenos Aires como un Estado soberano, razón por la cual desplegó una serie de iniciativas que se orientaron a lograr un control de una campaña asociada al federalismo. Una de ellas fue la instalación de las municipalidades en todo el territorio de la campaña bonaerense (Canedo, 2020).

La mirada tradicional sobre el Estado de Buenos Aires durante su separación de la Confederación Argentina ha puesto la atención principalmente en las disputas entre ambas entidades políticas durante toda la década y ha sido vista como un obstáculo en el camino de la conformación del estado-nación (Scobie, 1964). A partir de los aportes de Tulio Halperín Donghi (1982), la estructura política del Estado de Buenos Aires comenzó a ser pensada como un punto de inflexión en el desarrollo político posterior, permitiendo avanzar en las tensiones presentes en la coyuntura, entre las nuevas y las antiguas formas de la política. Trabajos más recientes aportan nuevas miradas del carácter "secesionista" de la nueva configuración estatal que se declara soberana, desde los debates jurídicos y los enfrentamientos con la Confederación Argentina (Aramburo, 2016) y con algunas parcialidades indígenas (Ratto, 2015). Significativos aportes orientaron la mirada hacia la dinámica interna a partir de los vínculos conflictivos que se produjeron entre las autoridades del poder central en los pueblos y los poderes locales, cuya idea gira en torno a explicar las dificultades que enfrentó el gobierno central para imponer su poder en toda la campaña bonaerense. Por caso, las dificultades que encontró la dirigencia porteña para consolidar un control político en las zonas rurales a partir de la creación de las prefecturas de campaña como consecuencia de las prácticas clientelares de los antiguos jueces de paz (Yangilevich, 2018), así como los obstáculos para la conformación y puesta en funcionamiento de las guardias nacionales en la campaña, en buena medida como consecuencia de la reticencia de los jueces de paz a colaborar con su organización, lo que se reflejó en su incapacidad para concretar el enrolamiento de los vecinos y formar los contingentes que se les demandaban para el servicio de frontera (Canciani, 2014).

En los últimos años se ha comenzado a indagar acerca del proceso de municipalización de la campaña bonaerense en tanto que posibilitó la asunción de prerrogativas por parte de las nuevas instituciones que se fueron dirimiendo entre diferentes actores políticos y niveles de gobierno (Canedo, 2019b). Constituyeron, además, una singularidad en la coyuntura general en tanto que la instalación de las municipalidades de campaña tuvo lugar al mismo tiempo en todo el territorio bajo jurisdicción del gobierno de Buenos Aires y cuya aplicación se dio en el marco de un heterogéneo mundo rural, sea por su ubicación geográfica, sea por las configuraciones históricas de cada caso (Canedo, 2020). 
La Ley de Municipalidades, sancionada en octubre de 1854 y reglamentada en febrero de 1856, constituyó la herramienta jurídica para la organización política y la construcción de un nuevo orden estatal e institucional en la campaña bonaerense.

Las municipalidades de campaña fueron planteadas por la ley como instituciones administrativas que debían limitarse a resolver los problemas de los pueblos (Zubizarreta, 2018: 108). En efecto, su art. 63 especificaba que "Los deberes de la Municipalidad serán: promover y consultar los intereses materiales y morales del pueblo, con absoluta prescindencia de los intereses políticos". ${ }^{2}$ Así lo reconocía Alsina en el debate en el Senado al exponer sobre las rentas, argumentando que las Municipalidades "ahora son únicamente cuerpos administrativos á quienes no competen ni funciones políticas ni judiciales; son cuerpos que en todos sus movimientos, para toda su existencia, están dependientes de los Supremos Poderes del Estado". ${ }^{3}$ Sarmiento, en su carácter de Jefe del Departamento de Escuelas, iba aún más lejos negando el carácter político de los actores locales. Consideraba que la institución municipal tenía

“...la ventaja de sustraer sus atenciones a las preocupaciones políticas, que tuercen, no pocas veces, las mejores intenciones; y el personal actual, compuesto de vecinos, en su mayor parte extraños a las cuestiones políticas, dan una garantía cierta de que los intereses morales, intelectuales y materiales de la ciudad, sean el objeto exclusivo de sus atenciones y cuidados." (Sarmiento, 1856: 80).

Ordenar institucionalmente la campaña y restarle protagonismo político fueron los objetivos de la élite política porteña.

La legislación de 1854 convirtió al juez de paz en el presidente de la municipalidad, nombrado por el gobierno del Estado de Buenos Aires a instancia de una terna elevada por la institución municipal que estaría integrada además por cuatro miembros titulares y dos suplentes, elegidos de forma directa por los vecinos del partido y cuya renovación sería por mitades cada año, mediante un sorteo en la última sesión de octubre de cada año. ${ }^{4}$ Cada miembro tenía una función establecida por la propia normativa (procurador, policial, instrucción pública y culto, recaudador municipal, etc.). ${ }^{5}$

\footnotetext{
2 Ley de Municipalidades, Recopilación, p. 713.

${ }^{3}$ Sesión del 10 de octubre de 1854. Diario de Sesiones de la Cámara de Senadores. Imprenta y Encuadernación "El Día". La Plata. 1995.

${ }^{4}$ Art. 60 de la Ley de Municipalidades, Recopilación, p. 713. Art. 1 Reglamento de las municipalidades de campaña, Recopilación, p. 782.

${ }^{5}$ Arts. 65 a 68 de la Ley de Municipalidades, Recopilación, pp. 679-680.
} 
A partir de la supresión del Cabildo de Buenos Aires y la sanción de ley electoral de agosto de 1821 el consenso político entendió que la legitimidad de las autoridades giraba en torno al sufragio, cuya frontera se fue ampliando considerablemente, abarcando a todo hombre libre mayor de 20 años o emancipado, nacido en el país o avecindado en él (Ternavasio, 2015). Durante la primera mitad del siglo XIX, la aplicación efectiva del principio representativo se circunscribió a las esferas del gobierno central en tanto que las autoridades locales de campaña fueron nombradas por el gobierno central (Gelman, 2000: 10). Era el gobernador quien elegía el juez de paz para cada año sobre la base de una terna presentada por el antecesor.

La instalación de las municipalidades de campaña vino entonces acompañada de novedades políticas: el pasaje de un órgano unipersonal a un órgano colegiado para la toma de decisiones, la aplicación del principio de representación en el plano del gobierno local y la potestad de elaborar colectivamente las ternas para juez de paz. Pero además implicó que la jurisdicción era el propio partido, a diferencia de las elecciones de diputados y senadores que nucleaban varios partidos en una sección electoral.

Si bien la Ley de Municipalidades fue sancionada el 11 de octubre de 1854, fue reglamentada el 2 de febrero de 1856, tras las elecciones para elegir municipales que se realizaron durante 1855 y el establecimiento de las primeras municipalidades a fines de enero de 1856. Estas primeras elecciones municipales en la campaña activaron tensiones sociales en las comunidades locales, lo que hizo que el gobierno tuviera que enfrentar un papel activo y plural de los habitantes de la campaña en la organización de cada municipalidad, junto con la coyuntura política más amplia de la etapa posrosista (Canedo, 2019a: 170).

\section{Dinámica institucional de la Municipalidad de Baradero}

Aunque la instalación de la Municipalidad de Baradero se produjo en febrero de 1856, a partir de 1854 y de forma simultánea en algunos partidos de la campaña (Canedo, 2019b), se conformó a instancias del gobierno central una Comisión Municipal provisoria constituida por una nómina de vecinos elevada por el Juez de Paz Julián Lynch, integrada por cuatro vecinos locales (Lino Piñeiro, Faustino Alsina, Pedro Ávila, Luis Villanueva) y dos extranjeros (Pedro Alonso y José Falconieri), aprobada en mayo de 1854 por el Superior Gobierno (Salaberry, 2009: 85), que constituyó una suerte de transición hacia el establecimiento definitivo que se daría un año y medio después.

La primera sesión de la municipalidad data del 4 de febrero de 1856 tras la aprobación de las elecciones del año anterior. Sin embargo, no hay en las actas municipales referencias al acto formal de instalación de las autoridades 
como sucedió en otros casos como San Isidro cuyo ceremonial incorporó un replique de campanas de la Iglesia, San Nicolás realizada en la Casa del Teatro o Dolores mediante un discurso del juez de paz poniéndolo en posesión del cargo (Canedo, 2019b). Surge como primer interrogante cómo fue la dinámica institucional. En el período considerado se llevaron adelante 166 sesiones, lo que demuestra un funcionamiento regular, con un promedio de dos reuniones por mes, cuando la reglamentación de la ley disponía una reunión mensual.

\section{CUADRO 1}

Sesiones municipales en Baradero. Distribución mensual 1856-1862

\begin{tabular}{|l|l|l|l|l|l|l|l|l|l|l|l|l|l|}
\hline & Ene & Feb & Mar & Abr & May & Jun & Jul & Ago & Sep & Oct & Nov & Dic & Total \\
\hline 1856 & $/ / / / /$ & 1 & 2 & 1 & - & - & 3 & 2 & - & 2 & - & - & 11 \\
\hline 1857 & 4 & 2 & 4 & 2 & 3 & 2 & 1 & 3 & 5 & 3 & 2 & - & 31 \\
\hline 1858 & 3 & 2 & 3 & 3 & 4 & 2 & 4 & 1 & 4 & 4 & 1 & 5 & 36 \\
\hline 1859 & 3 & 1 & 2 & 3 & 4 & 3 & 4 & 3 & 1 & 1 & 1 & 4 & 30 \\
\hline 1860 & 1 & 3 & 3 & 1 & 1 & 2 & 1 & 1 & 2 & 3 & - & 2 & 20 \\
\hline 1861 & - & 3 & 2 & 1 & 2 & - & 3 & 2 & 3 & - & 1 & 2 & 19 \\
\hline 1862 & 2 & 5 & 2 & 2 & 2 & - & 1 & 1 & 2 & 1 & 1 & - & 19 \\
\hline Total & 13 & 18 & 18 & 13 & 16 & 9 & 17 & 13 & 17 & 14 & 6 & 13 & 166 \\
\hline
\end{tabular}

Elaboración propia, datos extraídos del Libro de Acuerdos de la Municipalidad de Baradero (1856-1862)

Como se desprende del cuadro 1, el año más irregular y con menos sesiones fue 1856, con 11 sesiones y con 5 meses sin funcionamiento (no consideramos enero en tanto que empezó a funcionar en febrero). Es posible que la relativamente baja intensidad de sesiones del primer año, con un promedio de una reunión por mes, se explique por lo novedoso del sistema de funcionamiento de un gobierno local colegiado, luego de más de tres décadas de influencia del juez de paz como órgano unipersonal. En los siguientes 3 años se consolidó un funcionamiento regular y sistemático, con un ritmo promedio de 2,7 sesiones por mes, sufriendo una relajación entre 1860 y 1862 coincidiendo con el período comprendido entre las batallas de Cepeda y Pavón, aunque manteniendo una buena dinámica y sistematicidad. Entre 1857 y 1862 las reuniones fueron frecuentes, y en solo 7 meses (sobre 72) no se cumplieron conforme se establecía legalmente, lo que demuestra un mecanismo institucional que rápidamente se puso en marcha.

El interés de los municipales por el funcionamiento institucional se manifestó también en algunas resoluciones tomadas en los primeros años. Así, por ejemplo a principios de 1856 se consideró conveniente la realización de una 
reunión cada ocho días, el día franco de cada semana. ${ }^{6} \mathrm{Si}$ bien esto no se cumplió, se evidencia en lo sucesivo un aumento en la sistematicidad de las reuniones, aún después de la caída del promedio a partir de 1859, lo que pudo haber sido motivado por la coyuntura política caracterizada por el enfrentamiento militar entre Buenos Aires y la Confederación. A principios de 1857 se acordó que en cada primera reunión de mes cada miembro debía dar cuenta del trabajo realizado respecto de su competencia, exigencia que se instaba con cierta reiteración ante la falta de informes. ${ }^{7}$ No obstante, en algunos ramos como el de hacienda las rendiciones de cuentas anuales son más frecuentes.

Una práctica utilizada fue la conformación de comisiones "ad-hoc" integradas por los miembros municipales (uno o dos según el caso) y algunos vecinos del pueblo, para tratar diferentes asuntos de interés local, como la invitación a los "carreros del pueblo" para formar una comisión para "componer pantanos", para efectuar mensuras y mediciones de calles y manzanas. ${ }^{8}$ También se constituyeron para inspeccionar los exámenes públicos de la escuela de varones, para juntar fondos para la construcción de la Iglesia del pueblo y para la confección de un listado de personas que tuvieran ovejas pastando en terrenos del pueblo. ${ }^{9}$

Sobresale, además, una agenda amplia de temas tratados en las 166 sesiones, entre las que se destacan cuestiones relativas al ordenamiento territorial y la demarcación y medición de terrenos, el otorgamiento de solares, parcelas y su escrituración, la fundación de la colonia agrícola de inmigrantes suizos, la construcción de muelles, terraplenes, calzadas y bajadas al río, nomenclatura de calles. Otro aspecto sobre el que desarrollaron tareas fue el relativo al mantenimiento y funcionamiento de las escuelas de primeras letras del pueblo, la organización de exámenes públicos, la compra de mobiliarios y libros. Hubo también actividad en materia fiscal, elaborando los presupuestos de gastos e ingresos anuales, disponiendo variadas multas y tasas cuya recaudación redundaba en mejorar la caja de la municipalidad, así como disposiciones relativas al abasto. Por último, el órgano municipal canalizó reclamos de diversa índole de vecinos que presentaban sus demandas, como por ejemplo conflictos de límites entre propiedades, invasiones de ganado y pérdida del sembrado, solicitudes de explotación de zonas madereras y de adjudicación de solares. ${ }^{10}$

\footnotetext{
${ }^{6}$ Libro de Acuerdos Municipalidad de Baradero (Acuerdos), 14 de marzo de 1856.

${ }^{7}$ Acuerdos, 24 de enero, 01 de mayo y 07 de agosto de 1857, 05 de marzo y 14 de mayo de 1858.

${ }^{8}$ Acuerdos, 14 de marzo de 1857 y 07 de mayo de 1856.

${ }^{9}$ Acuerdos, 24 de julio de 1857, 22 de noviembre de 1857 y 08 de octubre de 1858.

${ }^{10}$ Las referencias, a modo de ejemplo, fueron extraídas de diferentes actas de sesiones.
} 


\section{La conformación de las ternas para Juez de Paz}

La normativa municipal colocaba por fuera del dispositivo electoral al juez de paz, erigido por la nueva ley en Presidente de la Municipalidad, quién seguiría siendo nombrado por decreto gubernamental, a partir de una terna vinculante elevada por la Municipalidad, en la última sesión de octubre de cada año, ${ }^{11}$ modalidad que implicó un cambio significativo en la medida en que tradicionalmente las ternas eran propuestas por el juez de paz saliente (Garavaglia, 1997; Gelman, 2000). Las ternas se votaban en la última sesión de octubre y se elevaban al Ministerio de Gobierno. El designado ejercería sus funciones el año siguiente. La legislación consideraba al Juez de Paz como "único conducto para comunicarse la Municipalidad con las autoridades y con los Jueces de Paz de los demás partidos del Estado y gefes militares establecidos en ellos". ${ }^{12}$ A partir de 1857 se eliminó el carácter vinculante de la terna elevada por los municipales (Corva, 2017), quitándole esta importante prerrogativa a la municipalidad, porque, en palabras del senador Portela, las ternas a veces no generaban "toda la confianza que el Gobierno deber tener en un Juez de Paz" (Canedo, 2020: 9)

En el cuadro 2 se detallan los ternados y los nombrados por el gobierno.

\section{CUADRO 2}

Ternas y nombramientos de Juez de Paz entre 1856 y 1862

\begin{tabular}{|l|l|l|}
\hline Año & Terna elevada & $\begin{array}{l}\text { Nombramiento } \\
\text { para el año } \\
\text { siguiente }\end{array}$ \\
\hline 1856 & Martín de Gainza, Mariano Basavilbaso, Félix Lynch & Martín de Gainza \\
\hline 1857 & Martín de Gainza, Félix Lynch, Fermín Rosell & Félix Lynch \\
\hline $1858^{13}$ & José Santos Gómez, Fermín Rosell, Ramón Basavilbaso & Juan San Martín \\
\hline 1859 & Luis Villanueva, Martín de Gainza, Fermín Rosell & Juan San Martin \\
\hline 1860 & $\begin{array}{l}\text { Francisco San Martin, Mariano Basavilbaso, Luis } \\
\text { Villanueva }\end{array}$ & $\begin{array}{l}\text { Francisco San } \\
\text { Martín }\end{array}$ \\
\hline 1861 & Fermín Rosell, Carlos Lynch, Fermín Castex & Fermín Rosell \\
\hline 1862 & Félix Lynch, Lino Piñeiro, Carlos Lynch & Luis Villanueva \\
\hline
\end{tabular}

Elaboración propia. Libro de Actas y Acuerdos de la Municipalidad de Baradero (18561862)

\footnotetext{
${ }^{11}$ Art. 61 de la Ley de Municipalidades, Recopilación, p. 713.

${ }^{12}$ Art. 64 de la Ley de Municipalidades, Recopilación. p.714

${ }^{13}$ En el cuadro solo se consignó la tercera terna que se confeccionó en ese año.
} 
En 1858 se elevaron 3 propuestas diferentes motivadas por la renuncia de los dos jueces de paz nombrados por el gobierno. La primera renuncia, de Fermín Rossell, motivó la elevación de una nueva terna definida el 29 de enero, integrada por Juan San Martín, Fermín y Feliciano Castex. ${ }^{14}$ El gobierno nombró a Juan San Martín pero no aceptó el cargo aduciendo que había sido electo como municipal, por lo que en marzo fue nombrado provisoriamente Fermín Castex, en tanto había integrado la terna anterior. ${ }^{15} \mathrm{Al}$ poco tiempo se elevó una nueva terna para cubrir la renuncia de San Martín, integrada por Félix Lynch, Ramón Basavilbaso y Antonio Carranza, ${ }^{16}$ siendo designado Félix Lynch. Finalmente, la tercera terna del año se propuso a fines de octubre, para el cargo del año siguiente, retomando de este modo el cumplimiento de lo dispuesto en la normativa.

En el período analizado se propusieron 11 vecinos para el cargo.${ }^{17}$ Fermín Rosell aparece en cuatro ternas, Martín de Gainza y Félix Lynch en tres y Mariano Basavilbaso, Luis Villanueva y Carlos Lynch en dos ocasiones. Los cinco restantes solo fueron ternados una vez. De todos ellos, hay solo dos ternados, Carlos Lynch y Santos Gómez, que no fueron nombrados como jueces de paz y tampoco electos como municipales.

Se verifica entonces una renovación de los nombres que ocuparon el cargo, con seis personas en siete años, lo que difiere de la última etapa del rosismo (1840-1852) en el cual hubo una tendencia permanecer como juez de paz varios años (Gelman 2000). ${ }^{18}$ Por otra parte, tres de los designados Villanueva, Juan y Francisco San Martín- ocuparon también el cargo de municipal, mientras que Gainza, Lynch y Rosell solo ejercieron como jueces de paz.

En general, las ternas se seleccionaron por unanimidad en cuerpo municipal, lo que pone de relieve una coincidencia en la consideración del personal idóneo para el principal cargo de la municipalidad. En la sesión de 22 de octubre de 1860, sin embargo, hubo diferentes propuestas en la candidatura al primer lugar de la terna que no permitieron mantener la unanimidad de los años anteriores, lo que hizo que el presidente ejerciera el derecho del voto doble

\footnotetext{
${ }^{14}$ Acuerdos, 29 de enero de 1858.

15 Acuerdos, 23 de abril de 1858.

16 Acuerdos, 14 de mayo de 1858.

$17 \mathrm{Si}$ contamos las dos ternas adicionales de 1858 se suman a la lista dos nombres, Antonio Carranza y Feliciano Castex.

18 Entre 1832 y 1851 hubo 4 vecinos ocupando el cargo de juez de paz. En 1832 y 1833 fue designado José Santos Gómez, volviendo al cargo entre 1838 y 1840 . Entre 1834 y 1836 el juez de paz fue Matías Carreras. En 1837, 1841, 1844 y 1845 estuvo a cargo Juan Magallanes y entre 1846 y 1848 Miguel Gerónimo Casco. No contamos con datos de 1842-1843-1849-1850-1851. Gelman (2000) tampoco encontró nombramientos para los últimos 3 años. Toda esta información proviene del Registro Oficial de la Provincia de Bs As de los diferentes años.
} 
para desempatar la votación. Mientras que los municipales Piñeiro y Frumento votaron por Juan San Martín (presidente), este y el municipal Basavilbaso votaron por Francisco San Martin. ${ }^{19}$ Esta facultad del juez de paz de desempatar una votación lo colocaba en una situación de relevancia, aunque en las actas de sesiones solo aparece utilizando esta potestad en la sesión mencionada.

Por último, se destaca que en 1858 y 1859, al haber dejado de ser vinculantes, el gobierno se apartó de las ternas elevadas y designó a Juan San Martín, quien no había sido propuesto en ninguna, posiblemente como forma de mediar en una disputa política interna, como veremos más adelante. En 1862 Luis Villanueva no había integrado la terna y no obstante el gobierno lo designo juez de paz para $1863 .{ }^{20}$

Se advierte la importancia que, para el gobierno central, seguía teniendo el cargo de Juez de Paz, ahora en el marco de un organismo colectivo de toma de decisiones. En los primeros años de funcionamiento municipal el Estado de Buenos Aires no intervino de forma directa, pero al poco tiempo se verifica un cambio legal que eliminó el carácter vinculante de las ternas elevadas, recurso que en Baradero fue utilizado en tres oportunidades. Es posible pensar que, tanto la eliminación del carácter vinculante de las ternas como la posibilidad de desempatar las votaciones, fueron dos recursos para asegurar un funcionamiento administrativo de las Municipalidades que la dirigencia porteña pretendió utilizarlos como contrapeso de la legitimidad política que tenía el órgano representativo municipal emergente del voto popular.

\section{La dimensión política de las elecciones municipales}

Los estudios sobre procesos electorales en el siglo XIX han realizado importantes contribuciones tanto para Hispanoamérica (Annino, 1995) como en particular sobre Buenos Aires, dando cuenta de la ampliación del cuerpo electoral que alcanzó a todos los hombres adultos libres, en un mecanismo representativo que funcionó como forma de legitimación del poder político atravesada de tensiones y conflictos entre diferentes actores con proyectos políticos diversos (Sabato, 1998; Ternavasio, 1995 y 2015). Particularmente en la campaña bonaerense se ha puesto el acento en las elecciones para componer la Sala de Representantes desde la ley electoral de 1821, poniendo de relieve que la participación política excedió ampliamente el ámbito de las élites para incluir a sectores medios y subalternos, que si bien no participaron en la toma de decisiones y en las elecciones con candidatos propios, contribuyeron activamente a legitimar la construcción del republicanismo, no solo a partir del acto del sufragio, sino mediante negociaciones y acuerdos, contraprestaciones e

\footnotetext{
${ }^{19}$ Acuerdos, 28 de octubre de 1860.
}

${ }^{20}$ Acuerdos, 11 de febrero de 1863. 
intercambios (Garavaglia, 2005; Lanteri y Santilli, 2010; Galimberti, 2014; Ternavasio, 2015).

Sin embargo, poco se conoce aún sobre las prácticas electorales para cargos municipales, pese a que algunos trabajos realizados señalan la relevancia otorgada por las comunidades locales a estas prácticas y la potencialidad para el estudio de los vínculos entablados entre gobiernos y redes políticas mayores (Martiren, 2010; Canedo, 2019a; 2019b y 2020; Galimberti, 2014).

Si la historiografía ha dado muestras de la politización de la campaña bonaerense revirtiendo la imagen tradicional que no veía vida política alguna (Garavaglia, 2005; Lanteri y Santilli, 2010; Galimberti, 2014; Zubizarreta, 2018) veamos cómo se expresó en los nuevos espacios municipales a partir de las siguientes cuestiones: ¿Cómo se conformó y quienes integraron el elenco de gobierno local? ¿Qué conflictos suscitaron y que relaciones con el poder central pusieron de manifiesto? ¿Cuál fue participación electoral? Para responder a estos interrogantes contamos con información de 11 elecciones municipales, de las cuales siete fueron principales -es decir, previstas en el calendario electoraly cuatro complementarias, convocadas para cubrir vacancias por renuncia. La información resulta dispar en razón de que proveniente de diversos tipos de fuentes. Sobre las primeras elecciones del 11 de marzo de 1855 contamos con el decreto de aprobación del poder ejecutivo, donde solo se mencionan los nombres de los electos. Para las demás elecciones (salvo 1861) disponemos con las actas de escrutinios emitidas por las mesas electorales, con lo que la información se amplía a cantidad y nombres de votantes, nombre de candidatos, integración de las mesas electorales. Por último, respecto de la elección del año 1861, del Libro de Acuerdos Municipales se pueden identificar los cesantes y los nuevos miembros.

\section{Conformación del elenco municipal}

En primer lugar, es preciso destacar que de los seis miembros que integraron la Comisión Municipal designada en 1854 dos (Luis Villanueva y Pedro Alonso) fueron elegidos para integrar la Municipalidad a partir de 1856, mientras que Piñeiro fue designado como juez de paz, lo que denota una continuidad.

El número de candidatos que participaron en las elecciones fue oscilante, con un pico en la elección en noviembre de 1856 convocada para elegir dos municipales titulares y un suplente en la que hubo 18 candidatos (diez para titulares y ocho para suplentes) y un piso en la última elección de noviembre de 1862 con dos candidatos para cubrir dos cargos de titulares y dos candidatos para cubrir un cargo suplente. 


\section{CUADRO 3}

Número de candidatos por elección general entre 1856 y 1862

\begin{tabular}{|l|c|c|c|c|}
\hline Elección & $\begin{array}{l}\text { Cargos a elegir, } \\
\text { Titulares/suplentes }\end{array}$ & $\begin{array}{l}\text { Candidatos } \\
\text { Titulares }\end{array}$ & $\begin{array}{c}\text { Candidatos } \\
\text { Suplentes }\end{array}$ & Total \\
\hline $\begin{array}{l}\text { Noviembre } \\
\text { de } 1856\end{array}$ & $2 / 1$ & 10 & 8 & 18 \\
\hline $\begin{array}{l}\text { Noviembre } \\
\text { de } 1857\end{array}$ & $2 / 0$ & 2 & - & 2 \\
\hline $\begin{array}{l}\text { Noviembre } \\
\text { de } 1858\end{array}$ & $2 / 1$ & 5 & 9 & 14 \\
\hline $\begin{array}{l}\text { Enero de } \\
1860\end{array}$ & $4 / 2$ & 4 & 3 & 7 \\
\hline $\begin{array}{l}\text { Octubre de } \\
1860\end{array}$ & $2 / 1$ & 2 & 2 & 4 \\
\hline $\begin{array}{l}\text { Noviembre } \\
\text { de } 1862\end{array}$ & $2 / 1$ & & 3 & 7 \\
\hline
\end{tabular}

Elaboración propia. Fuentes: AGN-EBA Legajos: 14586, 16123, 19333, 20647, 21557.

El cuadro 3 muestra la evolución del número de candidatos en elecciones principales, verificándose un importante impulso inicial en la contienda político-electoral. Sin embargo, en la siguiente elección la competencia se anula y se eligen los municipales por unanimidad. Vuelve a subir en ocasión de las disputadas elecciones de noviembre de 1858, para luego bajar a la mitad y mantener ese nivel en dos elecciones posteriores, cayendo, como señalamos, al nivel más bajo en 1862 .

Hay entonces tres momentos de competencia electoral: en noviembre de 1856, noviembre de 1858 y, en menor medida, octubre de 1860, aunque con una tendencia decreciente. Por su parte, en las elecciones de noviembre de 1857 se decidió por unanimidad, mientras que en enero de 1860 y noviembre de 1862 la competencia se limitó a un cargo suplente ya que hubo unanimidad en los cargos titulares.

En las elecciones complementarias, luego de un primer llamado en febrero de 1857 para cubrir dos renuncias donde hubo seis candidatos, en las tres elecciones restantes para cubrir sólo un cargo por ocasión no hubo competencia.

Surge de esto que quienes se hicieron de la municipalidad tras la primera elección intentaron mantener su posición en el órgano, lo que explicaría la tendencia a la reducción de candidaturas y la búsqueda de la unanimidad, no siempre lograda. 
Veamos ahora en el cuadro 4 quienes conformaron el elenco de gobierno local, entendido por tal al grupo de vecinos que, en cada año, integró el cuerpo municipal ya sea como juez de paz, como municipal titular o suplente.

\section{CUADRO 4}

Elenco municipal de Baradero entre 1856-1862

\begin{tabular}{|c|c|c|c|c|c|c|c|}
\hline Cargos & 1856 & 1857 & 1858 & 1859 & 1860 & 1861 & 1862 \\
\hline $\begin{array}{l}\text { Juez de } \\
\text { Paz }\end{array}$ & LinoPiñeiro & $\begin{array}{l}\text { Martínde } \\
\text { Gainza }\end{array}$ & FélixLyndh & $\begin{array}{l}\text { JuanSan } \\
\text { Martín }\end{array}$ & $\begin{array}{l}\text { JuanSan } \\
\text { Martín }\end{array}$ & $\begin{array}{l}\text { Francisco } \\
\text { SanMartin }\end{array}$ & $\begin{array}{l}\text { Fermín } \\
\text { Rosell }\end{array}$ \\
\hline \multirow[t]{4}{*}{ Titulares } & $\begin{array}{l}\text { Pedro } \\
\text { Alonso }\end{array}$ & $\begin{array}{l}\text { Pedro } \\
\text { Alonso }\end{array}$ & $\begin{array}{l}\text { Pedro } \\
\text { Alonso }\end{array}$ & $\begin{array}{l}\text { Pedro } \\
\text { Alonso }\end{array}$ & $\begin{array}{l}\text { Francisco } \\
\text { SanMartín }\end{array}$ & $\begin{array}{l}\text { Domingo } \\
\text { Frumento }\end{array}$ & $\begin{array}{l}\text { Luis } \\
\text { Villanueva }\end{array}$ \\
\hline & $\begin{array}{l}\text { Francisco } \\
\text { SanMartín }\end{array}$ & LinoPiñeiro & LinoPiñeiro & $\begin{array}{l}\text { Lino } \\
\text { Piñeiro }\end{array}$ & LinoPiñeiro & $\begin{array}{l}\text { Lino } \\
\text { Piñeiro }\end{array}$ & $\begin{array}{l}\text { Lino } \\
\text { Piñerio }\end{array}$ \\
\hline & $\begin{array}{l}\text { Mateo } \\
\text { Muyños }\end{array}$ & $\begin{array}{l}\text { Germán } \\
\text { Frers }\end{array}$ & $\begin{array}{l}\text { JuanSan } \\
\text { Martín/ } \\
\text { Germán } \\
\text { Frers }\end{array}$ & $\begin{array}{l}\text { Germán } \\
\text { Frers }\end{array}$ & $\begin{array}{l}\text { Ramón } \\
\text { Basavillbaso }\end{array}$ & $\begin{array}{l}\text { JuanSan } \\
\text { Martín }\end{array}$ & $\begin{array}{l}\text { Domingo } \\
\text { Leavini }\end{array}$ \\
\hline & $\begin{array}{l}\text { Luis } \\
\text { Villanueva }\end{array}$ & $\begin{array}{l}\text { Mariano } \\
\text { Basavillbaso }\end{array}$ & $\begin{array}{l}\text { Mariano } \\
\text { Basavilbaso }\end{array}$ & $\begin{array}{l}\text { Luis } \\
\text { Villanueva }\end{array}$ & $\begin{array}{l}\text { Domingo } \\
\text { Frumento }\end{array}$ & $\begin{array}{l}\text { Luis } \\
\text { Villanueva }\end{array}$ & $\begin{array}{l}\text { Germán } \\
\text { Frers }\end{array}$ \\
\hline \multirow[t]{2}{*}{ Suplentes } & $\begin{array}{l}\text { Ignacio } \\
\text { Pereira }\end{array}$ & $\begin{array}{l}\text { Ignacio } \\
\text { Pereira }\end{array}$ & $\begin{array}{l}\text { Federico } \\
\text { Alonso }\end{array}$ & $\begin{array}{l}\text { Federico } \\
\text { Alonso }\end{array}$ & $\begin{array}{l}\text { Blas } \\
\text { Pianzola }\end{array}$ & JoséPavía & JoséBolaño \\
\hline & $\begin{array}{l}\text { Mariano } \\
\text { Basavilbaso }\end{array}$ & $\begin{array}{l}\text { Faustino } \\
\text { Alsina }\end{array}$ & $\begin{array}{l}\text { Domingo } \\
\text { Frumento }\end{array}$ & (Nofigura) & JoséPavia & $\begin{array}{l}\text { Juan } \\
\text { Acosta }\end{array}$ & $\begin{array}{l}\text { Juan } \\
\text { Acosta }\end{array}$ \\
\hline
\end{tabular}

Elaboración propia, datos extraídos del libro de acuerdos de la Municipalidad de Baradero (1856-1862)

Algunas personas se repiten con cierta regularidad (Piñeiro, Frers, Villanueva, San Martín, Basavilbaso, Alonso), mientras que otros aparecen solo una o dos veces. Esto indica que una pequeña parte del elenco político municipal se mantiene estable mientras que otra un poco más numerosa va rotando. Hubo, a lo largo de todo el período, 30 cargos electivos (seis en la elección inicial de 1855 y la renovación de tres cargos por año) ${ }^{21}$ que fueron ocupados por 19 vecinos. En este punto, sucede algo diferente a lo que Marcela Ternavasio $(1999 ; 133)$ identifica como uno de los rasgos característicos de la unanimidad rosista, en el sentido de la repetición de los mismos nombres en tanto que, como la renovación de la Sala era por mitades, los diputados salientes eran reelectos, constituyéndose un elenco estable de miembros de la Sala de Representantes. Veamos en nuestro caso con los miembros municipales titulares: en 1856 resultaron cesantes Francisco San Martin y Luis Villanueva y

${ }^{21}$ Si bien en enero de 1860 la elección se convocó para cubrir la totalidad de los cargos, en 1859 no se realizaron elecciones. 
ninguno fue electo para 1857. ${ }^{22}$ En 1857 resultaron cesantes Basavilbaso y Frers, siendo electo para el año siguiente sólo el primero. ${ }^{23}$ En 1858 cesaron Pedro Alonso y Lino Piñeiro, resultando electos Francisco San Martín y Juan Benito Acosta (veremos luego la impugnación efectuada). ${ }^{24}$ En 1859 no se realizaron las elecciones como consecuencia de la batalla de Cepeda y se volvieron a normalizar en enero de 1860 la cual se convocó para elegir la totalidad de los miembros municipales, solo repitiendo el cargo de titular Lino Piñeiro. ${ }^{25}$ En 1861 cesaron Juan San Martín y Domingo Frumento pero no fueron electos para integrar la municipalidad del año siguiente. ${ }^{26}$ Solo hacia el fin del período, en 1862 no hubo recambio en tanto que habiendo resultado cesantes Lino Piñeiro y Luis Villanueva en la sesión del 26 de octubre, fueron electos en las elecciones de noviembre para integrar la municipalidad en 1863. ${ }^{27}$ Resumiendo, sobre 14 cargos titulares que se renovaron, solo se reeligieron cuatro municipales que habían sido declarados cesantes. En el caso de los suplentes ninguno volvió a asumir el cargo inmediatamente después de quedar cesantes. Si bien la competencia fue variable y con tendencia decreciente, no se verifica una reelección de los municipales salientes, sino una renovada composición de la municipalidad. La existencia en determinadas ocasiones de múltiples candidatos a municipales (titulares y suplentes) revela, además, la posibilidad de una ampliación del elenco de gobierno local.

¿Quiénes ocuparon los cargos? La información sobre los perfiles socioeconómicos de los municipales y jueces de paz es incompleta, aunque podemos hacer una reconstrucción parcial de alguno de ellos. Lino Piñeiro, miembro permanente del elenco municipal, era médico en ejercicio y propietario de tierras (Salaberry, 2019). Germán Frers educador, había ejercido el cargo de Inspector General de Escuelas en 1853 hasta su nombramiento como director de la Escuela Normal Femenina en 1855, creada por la Sociedad de Beneficencia (Newland, 1992: 149), se hallaba vinculado a una importante red familiar a partir de su matrimonio con la hija de Patricio Lynch, el jefe de una familia de notables y terratenientes con vínculos con el gobierno porteño, quién había desempeñado como regidor del Cabildo en 1817 y había sido electo diputado por la ciudad para integrar la Sala de Representantes tras la caída de Rosas. También integraban esta familia Félix, Carlos y Julián Lynch (Ibarguren Aguirre, 2016: 23, 45). Por su parte, Martín de Gainza, también parte de la familia Lynch, era miembro de la Guardia Nacional, nombrado Comandante

\footnotetext{
22 Acuerdos, 24 de octubre de 1856 y AGN-EBA, Sala X, 28-11-13, legajo 14586

${ }^{23}$ Acuerdos, 25 de octubre de 1857 y AGN-EBA, Sala X, 29-2-8, legajo 16123.

${ }^{24}$ Acuerdos, 31 de octubre de 1858 y AGN-EBA, Sala X, 29-4-2 legajo 17865.

${ }^{25}$ Archivo General de la Nación-Estado de Buenos aires (AGN-EBA), Sala X, 29-5-7, legajo 19333.

${ }^{26}$ Acuerdos, 7 de noviembre de 1861.

${ }^{27}$ Acuerdos, 26 de octubre de 1862 y AGN-EBA, Sala X, 29-7-5, legajo 21557.
} 
del Batallón Norte en junio de $1859^{28}$ y posteriormente Inspector General de Milicias en 1862, cargo creado ese mismo año, ${ }^{29}$ posteriormente nombrado Ministro de Guerra y Marina bajo la presidencia de Sarmiento, iba a tener en el futuro un destacado rol en el levantamiento de Tejedor de 1880 (Sabato, 2008). La familia San Martín, por su parte, aparece en los registros oficiales como hacendados y propietarios de grandes extensiones de tierra. ${ }^{30}$ Cabe además mencionar que dos de ellos, Domingo Frumento -municipal en 1860 y 1861- y Francisco Bianchi -electo municipal para 1863- provenían de la estructura eclesiástica (Alfonso Rafaelli también era cura y aunque participó de la elección de 1856 no resultó electo municipal). Por otra parte, la disputa electoral municipal abrió la posibilidad a la participación política de extranjeros. Germán Frers había arribado a Buenos Aires en 1843 proveniente de Alemania, mientras que Pedro Alonso, José Falconieri, José Iribar y Federico Alonso eran de nacionalidad española (Salaberry, 2009).

\section{Conflictos y relaciones de poder}

Si bien el elenco de gobierno tuvo permanencia y cambios y se fue ampliando a medida que se llevaban adelante las elecciones, no conformaron un bloque homogéneo. Muy pronto aparecieron disputas políticas cuyo escenario fue la institución municipal. Dos episodios dan cuenta de esta situación.

Una situación conflictiva se produjo en torno a las elecciones realizadas en noviembre de 1858, que implicaron impugnaciones electorales, disputas políticas, estrategias de movilización y vínculos políticos con el gobierno central. De la elección, convocada para el reemplazo de dos titulares y un suplente para el año 1859, participaron 188 electores. El resultado fue: para municipales titulares Francisco San Martin obtuvo 119 votos, Juan Benito Iglesias 119, Lino Piñeiro 69, Pedro Alonso 68 y Ramón Basavilbaso 1. Para suplentes, hubo 123 votos a Ignacio Pereyra, 119 para Lorenzo Iribar, 69 a Juan Benito Iglesias, 58 a Federico Alonso, tres votos para Nicolás Martínez, dos a Francisco San Martin y un voto para Ramón Basavilbaso, Germán Frers y Avelino Martínez. ${ }^{31}$ Hubo en total 14 candidatos disputando tres cargos.

Unos días después Germán Frers, municipal en funciones, impugnó la elección en una carta dirigida al entonces senador Domingo F. Sarmiento, fechada el 15 de noviembre de 1858, informándole sobre la presentación de una lista "capitaneada por los San Martín" y dando una pequeña caracterización de cada uno:

\footnotetext{
${ }^{28}$ ROGBA (1859), Decreto del 27 junio de 1859, p. 59.

${ }^{29}$ AGN-EBA, Sala X 29-7-4, legajos 21441 y 21442.

${ }^{30}$ Archivo Municipal de Baradero (AMB), Prefecto de campaña, 1858, Exp. Nro 5.

${ }^{31}$ AGN-EBA, Sala X 29-4-2, legajo 17865.
} 
“La lista San Martín reúne las siguientes condiciones: Hay ya un San Martín municipal, que no hace nada. En la nueva lista entra Francisco San Martin, primo hermano del primero. Juan Benito Iglesias, español, hombre tramposo y completamente desacreditado y senil. Ignacio Pereira, cuñado de San Martín, y también completamente desacreditado por trampas y mala conducta. José Iribar, españolito carpintero, que recién se ha puesto de bolichero. Son casi todos los nombrados hombres rudos, incapaces de tener un pensamiento, de realizar una idea." 32

Si bien se puede advertir cierta preocupación sobre las condiciones intelectuales (la apelación a sentencias como hombres rudos, incapaces de tener un pensamiento, de realizar una idea) y morales (hombre tramposo, mala conducta) de este grupo, su principal argumento radicaba en que formarían una mayoría dentro del cuerpo municipal, lo cual le permitiría incidir en beneficio de los negocios propios. Denunciaba que la familia San Martín había tomado posesión de los terrenos del pueblo y había entablado un pleito con la municipalidad que no estaba resuelto, por lo que consideraba que "mal se pueden administrar intereses públicos, si están éstos en oposición con intereses de familia.". ${ }^{33}$ En la misma carta explicaba qué había sucedido en la jornada: "cuando nadie creía que tuviera oposición la lista preparada y compuesta con poca diferencia de los mismos que componían la municipalidad anterior", aparecieron "unos cuantos gauchos electores" movilizados por los San Martín para torcer el normal rumbo de las elecciones. ${ }^{34}$

Esto da cuenta, por un lado, de una búsqueda de unanimidad electoral bajo la premisa del "normal rumbo de las elecciones" y, por otro, de la movilización política que significaban las elecciones, que, lejos de ser un simple acto administrativo al servicio del poder de turno, constituía un eventual campo de disputas y tensiones. De hecho, de la confrontación de los registros electorales de los años 1856 y 1857 con el acta de 1858, se verifica que solo ocho de los 119 votantes de la lista de San Martín en 1858 participaron de las anteriores, lo cual señala el armado de una estrategia de movilización para intervenir decididamente en el sufragio de $1858 .{ }^{35}$ La participación electoral de esos "gauchos electores" da cuenta que los resultados electorales no estaban necesariamente prefijados de antemano.

\footnotetext{
${ }^{32}$ Archivo del General Mitre-Ministerio de Relaciones Exteriores 1858-1859 ( AGM-MRE), Tomo XIX, Imprenta Sopena, Provenza, Biblioteca de la Nación, Buenos Aires, 1912, pp. 89/90.

${ }^{33}$ AGM-MRE, p. 90.

${ }^{34}$ AGM-MRE, p. 89.

${ }^{35}$ AGN-EBA, Sala X, 29-4-2, legajo 17865, Sala X, 28-11-13, legajo 14586 y Sala X, 29-2-8, legajo 16123.
} 
Los motivos que expone Frers están orientados a deslegitimar el accionar y el resultado electoral, buscando que prospere su impugnación. Sin embargo, es preciso advertir que no se trataba de un grupo político nuevo en el escenario local. Juan y Francisco San Martín habían sido candidatos en elecciones anteriores, en las cuales resultaron electos. ${ }^{36}$ Además, como vimos, Juan San Martín había renunciado a su designación como juez de paz a principios de año argumentando que era municipal, lo que da cuenta de una estrategia política para conseguir nuevos cargos para su grupo. También Ignacio Pereira había sido municipal suplente en 1856 y 1857, mientras que Juan Iglesias había resultado electo en las elecciones de 1856 renunciado al cargo al poco tiempo. ${ }^{37}$

A falta de fuentes oficiales, podemos inferir que la intervención del gobierno de Buenos Aires se orientó a una suerte de equilibrio político entre ambos grupos, en la medida en que para 1859 fue nombrado Juan San Martín como juez de paz, pero ninguno de los miembros de la lista impugnada por Frers aparece como municipal en las sesiones del año siguiente, lo que sugiere que la elección no fue aprobada por el Ministerio de Gobierno. Posteriormente, Juan San Martín será juez 1860 y municipal en 1861, mientras que Francisco San Martin será municipal en 1860 y juez de paz en 1861.

El segundo conflicto que tuvo como escenario la institución municipal fue el levantamiento federal liderado por Vicente Troncoso dos días después de finalizada la batalla de Cepeda, el 25 de octubre de 1859 en la que las tropas de la Confederación Argentina comandadas por Justo José de Urquiza venció militarmente a las tropas de Buenos Aires al mando de Bartolomé Mitre. Acompañado por un grupo de alrededor de 40 personas, Troncoso se hizo cargo de la municipalidad, declaró cesantes las autoridades legítimas y dispuso de los fondos públicos para pagarle una suma de dinero a sus seguidores. La proclama se pronunciaba "en favor de la Causa Nacional, sin más aspiraciones que la de ver unido a mi país unidas á sus hermanas las demás provincias de la Confederación Argentina", 38 invocando de una legitimidad basada en la concepción del ciudadano en armas, como parte del régimen republicano, en el que el uso de la fuerza constituyó una forma legítima de impugnación a los gobernantes de turno cuando se consideraba que estos violaban la libertad (Sabato, 1998; 2008).

El episodio es significativo porque fue el propio Urquiza quien le ordenó al líder del grupo armado para que "obedeciera ciegamente al señor Gobernador de Buenos Aires, debiendo ponerse bajo sus órdenes", lo que fue aceptado por Troncoso. ${ }^{39}$

\footnotetext{
${ }^{36}$ AGN-EBA, Sala X, 28-11-13, legajo 14586 y Sala X, 29-2-8, legajo 16123.

${ }^{37}$ AGN-EBA-, Sala $X, 28-11-13$, legajo 14586

38 AGN-EBA, Sala X, 29-3-11, legajo 17492.

${ }^{39}$ AGN-EBA, Sala X, 29-3-11, legajo 17492, Acuerdos, 6 de diciembre de 1859.
} 
Si, como demuestra Flavia Macías (2019), Urquiza toleró que los gobernadores de provincias reivindicaran para sí la práctica bélica entablando en guerras interprovinciales en función de la adhesión de las provincias al nuevo proyecto nacional, no se verifica este mismo criterio de aceptación de la violencia armada en el conflicto municipal analizado, toda vez que dispuso desarmar a su grupo afín y subordinarlo al gobierno de Buenos Aires al que había derrotado militarmente pocos días antes. El sentido de la intervención de Urquiza en este conflicto en el que estaba en juego la unificación de Buenos Aires, se orientó a una suerte de control de daños, lo cual resulta compatible con la cláusula del Pacto de San José de Flores firmado el 11 de septiembre de 1859 que aseguraba que los establecimientos públicos de Buenos Aires seguirían gobernados y legislados por las autoridades de la provincia. ${ }^{40}$ En este sentido, la desmovilización fue militar pero también política, ya que no solo tuvieron que deponer las armas sino someterse al gobierno de Buenos Aires, reintegrar la Municipalidad a su situación anterior y devolver los fondos utilizados. Otra consecuencia del levantamiento fue la renuncia indeclinable del municipal tesorero Pedro Alonso ante la negativa de los demás miembros municipales que manifestaron que debía reasumir el cargo porque así lo exigía la buena moral. ${ }^{41}$

Ambos conflictos ponen en evidencia el juego de estrategias y adhesiones políticas de los actores locales, su integración a redes de poder más amplias y las intervenciones desplegadas por las instancias superiores en función de sus propios objetivos.

\section{Participación electoral}

Para analizar la participación de votantes seguiremos el criterio desarrollado por Agustín Galimberti (2021) a fin de medir su relación respecto población total como del padrón potencial de votantes. En 1815 su población era de 1.151 habitantes y para 1822 ascendía a 1.832 (Mateo, 2013: 114). En 1854 se realizó un relevamiento de habitantes de la campaña a partir de los informes elevados por los jueces de paz de cada pueblo. La iniciativa apuntaba a conocer en detalle el estado poblacional de la campaña para una reorganización integral. Según ese registro estadístico redactado por Justo Maeso, la población total de Baradero era de 2.603 habitantes. ${ }^{42}$ Según el censo oficial de 1869, la población total

40 Artículo 7 del Pacto de San José de Flores. Extraído de: https://hum.unne.edu.ar/academica/departamentos/historia/catedras/hist argen indep/pactos $\mathrm{t}$ rat acuer/pacto san jose flores.pdf

${ }^{41}$ Acuerdos, 26 de noviembre de 1859.

42 Archivo Histórico Provincial (AHP), Registro Estadístico del Estado de Buenos Aires redactado por Justo Maeso. Segunda época, Números 5 y 6, Imprenta Porteña, 1855. En 1858 una actualización de los datos estadísticos fue confeccionado por Diego G. Fuente, pero en el 
ascendía a 4.919, entre hombres y mujeres. Tenemos entonces que, entre 1854 y 1869 , la tasa anual de crecimiento poblacional fue del $4,33 \%$, con lo que, a falta de datos más precisos, podemos proyectar una estimación de la evolución poblacional local. La siguiente cuestión es reconstruir el padrón potencial de votantes de Baradero en el período comprendido entre 1856 y 1862. Como del registro estadístico de 1854 no surgen distinciones por edades ni por género, recurrimos el censo nacional de 1869, el más cercano en el tiempo al período analizado, del cual surge que había 1.159 personas mayores de 20 años habilitadas para votar, ${ }^{43}$ lo que representaba un $23 \%$ del total de la población de ese momento. ${ }^{44}$ Como resulta imposible identificar la cantidad de mayores de 18 años casados en cada año, metodológicamente solo consideramos para la reconstrucción del padrón a los mayores de 20 años, habilitados a votar por la Constitución de 1854.

Siguiendo esta proyección, para la primera elección de 1856 la población sería de 2.834. Si damos por cierto que el porcentaje de votantes se mantuvo en el $23 \%$ de la población y proyectamos en retrospectiva, sobre el total de 2.834 habitantes en 1856 el padrón potencial de votantes alcanzaría a 652 personas. Como se ve, se trata de una población en crecimiento, que a mediados de siglo contaba con un importante padrón de habilitados a ejercer el sufragio.

En el cuadro 5 podemos ver la incidencia de la cantidad de votantes en la evolución tanto de la población estimada como del padrón potencial de votantes.

caso de Baradero se repite el número de habitantes de 1854. Pocos pueblos registran cambios, por lo que presumiblemente no todas las autoridades informaron nuevos datos. https://catalogo.bn.gov.ar/F/?func=direct\&doc number=001282397\&local base=GENER. Por ello tomaremos la cifra del registro de 1854 para las proyecciones.

${ }^{43}$ Primer Censo de la República Argentina verificado en los día 15, 16 y 17 de septiembre de 1869. Buenos Aires, Imprenta del Porvenir, 1872. Pp. 28-29 (81/82).

${ }^{44}$ En el citado artículo de Galimberti (2021) se reconstruye el padrón potencial de votantes a partir de los datos de los padrones de 1813 y 1815 en los que constan las variables de edad y sexo, extrapolados a los momentos analizados. Para 1854 en la campaña identifica 180.257 habitantes y un padrón potencial de 51.356 votantes, lo que representa un $28 \%$ del total de habitantes, porcentaje cercano al 23\% que reconstruimos en el caso particular de Baradero. 


\section{CUADRO 5}

Cantidad de votantes y porcentajes sobre cantidad de habitantes y sobre padrón potencial entre 1856 y 1862

\begin{tabular}{|l|c|c|c|c|c|}
\hline Elección & Habitantes & $\begin{array}{l}\text { Padrón } \\
\text { potencial }\end{array}$ & Votantes & $\begin{array}{l}\text { Porcentaje } \\
\text { sobre cantidad } \\
\text { de habitantes }\end{array}$ & $\begin{array}{l}\text { Porcentaje } \\
\text { sobre padrón } \\
\text { potencial }\end{array}$ \\
\hline 1856 & 2.834 & 652 & 266 & 9,4 & 40,7 \\
\hline 1857 & 2.956 & 680 & 143 & 4,8 & 21 \\
\hline 1858 & 3.084 & 709 & 188 & 6 & 26,5 \\
\hline 1860 (ene) & 3.358 & 772 & 96 & 2,8 & 12,4 \\
\hline 1860 (nov) & 3.358 & 772 & 195 & 5,8 & 25,25 \\
\hline 1862 & 3.655 & 841 & 65 & 1,7 & 7,7 \\
\hline
\end{tabular}

Elaboración propia sobre la base del Registro Estadístico de 1854 y del Censo Nacional de 1869 y AGN-EBA Legajos: 14586, 16123, 19333, 20647, 21557.

Hay una tendencia a la disminución en la participación de votantes, aunque no en forma lineal, sino con oscilaciones, pasando del $40,7 \%$ al $7,7 \%$ del padrón potencial de votantes y del 9,4\% al 1,7\% de los habitantes. Dentro del descenso general, aparece un aumento relativo en 1858, lo cual se explica, como vimos, por la movilización electoral organizada. ${ }^{45}$ Otro aumento del porcentaje de votantes se dio en noviembre de 1860, luego de la baja participación en la elección municipal de enero de ese año (elección que no se pudo organizar en noviembre de 1859 como consecuencia de la batalla de Cepeda). Ambos aumentos coinciden, además, con elecciones en la sección electoral, para integrar la Sala de Representantes (Galimberti, 2021), por lo que es posible pensar que la realización de elecciones de diputados o senadores repercutieron favorablemente en las elecciones municipales.

Estas cifras nos dan una idea aproximada de la cantidad de vecinos que tenían derecho al sufragio y cuál fue la incidencia de la participación electoral tanto en relación a la cantidad de votantes como en relación al padrón potencial. Si comparamos con el período rosista (aclarando que se tratan de elecciones diferentes en la medida en que solo se convocaban para elegir miembros de la Sala de Representantes), vemos que la participación electoral disminuyó en relación a la población. Así, por ejemplo, en las elecciones de 1839 hubo 320 votantes (Ternavasio, 1999). En 1842 votaron 389 personas, en las elecciones de 1844 participaron 479 sufragantes, mientras en las elecciones de

${ }^{45}$ AGM-MRE, p. 89. 
1850 hubo 372 votos (Galimberti, 2021), muy por encima del pico de 266 electores en las elecciones municipales de 1856. Es posible conjeturar que un descenso en la cantidad de votantes fuera visto por el elenco de gobierno como el mejor escenario a la hora de mantenerse en los cargos municipales.

Quedan, no obstante, algunos interrogantes por indagar, como por ejemplo si se repiten los votantes en las diferentes elecciones y cómo fue la participación en las elecciones para elegir senadores y representantes.

\section{Conclusiones}

Las prácticas electorales para cargos municipales en la campaña bonaerense a mediados de siglo posibilitaron la emergencia y conformación de nuevos elencos de gobierno local y una articulación con el Estado de Buenos Aires, a partir de instancias de acuerdos, tensiones y conflictos que se suscitaron entre los diferentes actores políticos, en el cual la municipalidad se constituyó como un canal importante para la práctica política. A partir de la cuestión de las ternas y la selección de los jueces de paz se intentó problematizar la relación entre el ejercicio de la soberanía de los poderes locales por un lado y la soberanía del Estado de Buenos Aires por el otro, en la cual, si bien hubo un recambio del personal, no es menos cierto que cuando lo dispuso, el gobierno central impuso su propio criterio para la designación de jueces de paz. El pasaje de un mecanismo político institucional en donde la autoridad local era elegida directamente por el gobierno central, a una forma en la que se complementaban el nombramiento del juez de paz por parte del gobierno con la elección directa de los miembros municipales y suplentes por parte de los vecinos de los partidos significó, para los vecinos de Baradero, la oportunidad de elegir sus propias autoridades, aunque matizado en la práctica a partir de 1858 en razón de la selección del juez de paz por parte del poder central sin la obligación de tener en cuenta las ternas elevadas.

La incorporación de nuevos actores políticos a un armado institucional basado en el principio de la representación política como forma de legitimación generó la preocupación del elenco más estable por mantenerse en el poder local, lo que se pone de manifiesto con la tendencia a la unanimidad electoral. Sin embargo, la práctica del sufragio constituyó en ocasiones un campo de competencias y disputas entre diferentes actores políticos con vínculos diversos con el gobierno central. Además, la pertenencia a redes políticas y familiares representó un insumo relevante para el acceso o mantenimiento de los cargos públicos. De esta forma se constituyeron diversos actores locales que articularon con otros actores e instancias estatales. En este punto, sostenemos que no existió un elenco municipal homogéneo y reducido, aun cuando algunos aparezcan ocupando cargos varios años seguidos. 
Desde una perspectiva que tuvo en cuenta la historia política de actores, analizamos el elenco de gobierno que se constituyó a partir de los mecanismos de representación política aplicados al nivel municipal. Observamos cómo grupo de vecinos alcanzó, ejerció y en ocasiones disputó cargos políticos, electivos y no electivos. La introducción del sufragio para elegir representantes locales amplió cualitativamente la participación política de los habitantes de la campaña, llamados ahora a intervenir en el cercano espacio de sus pueblos, aun cuando esa ampliación no se verifica en términos cuantitativos, es decir en cantidad de votantes. El sufragio se constituyó en una nueva fuente de legitimación de los poderes locales en el marco de la configuración de un sistema representativo al interior del Estado de Buenos Aires. Pero también, desde el gobierno central, esa participación apuntaba a crear instituciones a partir de las cuales construir poder y legitimidad en la campaña.

En Baradero, se verifica una participación de votantes que fue de mayor a menor, pero no en forma directa y lineal, sino con oscilaciones, en la que no fue ajena la movilización electoral y los conflictos políticos por el control de los cargos. Sin embargo, el cuerpo de votantes consolidó la municipalidad, con una dinámica institucional sostenida, cuyo ritmo fue muy superior a lo que la legislación preveía y ocupándose de un amplio abanico de temas.

\section{Referencias bibliográficas}

Annino, A. (1995). Historia de las elecciones en Iberoamérica. Siglo XIX, FCE.

Aramburo, M. (2016). El debate legislativo de la Constitución del Estado de Buenos Aires (1854). Los conceptos de soberanía, nación y Estado. Revista PolHis, 9 (17), enero-junio, 170-209.

Archivo del General Mitre. Ministerio de Relaciones Exteriores 1858-1859, (1912). Buenos Aires, Biblioteca de la Nación.

Archivo del General Mitre. Campaña de Cepeda 1858-1859 (1912) Buenos Aires, Biblioteca de la Nación.

Barcos, F. (2012). Expresiones políticas y movilización popular en los pueblos de la campaña de Buenos Aires. La Guardia de Luján y el Sitio de Lagos (18521854). Revista Nuevo Mundo Mundos Nuevos, Debates.

Canciani, L. (2014). Es preciso, pues, regimentar. La organización de la Guardia Nacional de campaña. Buenos Aires, 1852-1862. Anuario del Instituto de Historia Argentina, (14).

Canedo, M. (2016). Los municipios decimonónicos en hispanoamérica. Modelos y casos en perspectiva comparada. Travesía, Suplemento. VII Reunión del Comité Académico de Historia, Regiones y Fronteras - AUGM 
Canedo, M. (2019a). “...en la campaña se ha despertado un espíritu maligno”. Estrategias políticas y divisiones sociales en las primeras elecciones municipales (Estado de Buenos Aires, 1855). Illes i Imperis, Universitat Pompeu Fabvra, (21), 167-193.

Canedo, M. (2019b). La instalación de las municipalidades de campaña en el estado de Buenos Aires. Un análisis desde sus actas de sesiones (1856-1858). Revista de Historia Americana y Argentina, 54 (1), Universidad Nacional de Cuyo, 177-209.

Canedo, M. (2020). Municipalidades en "todo el territorio". Desafíos en la conformación del Estado de Buenos Aires. Historia Regional. Sección Historia. ISP № 3, Año XXXIII (42), enero-junio, 1-16.

Corva, M. A. (2017). La elección popular de los jueces de paz en la provincia de Buenos Aires. Fracaso y conflicto de poderes. Derechos En Acción, (4). [en línea] https://doi.org/10.24215/25251678e047.

Diario de Sesiones de la Cámara de Senadores (1995), La Plata: Imprenta y Encuadernación “El Día”.

Garavaglia, J. C. (2005). Elecciones y luchas políticas en los pueblos de la campaña de Buenos Aires: San Antonio de Areco (1813-1844). Boletín del Instituto de Historia Argentina y Americana "Dr. Emilio Ravignani", Tercera serie (27), 1er. semestre, 49-74.

Garavaglia, J. C. (1997). Paz, orden y trabajo en la campaña: la justicia rural y los juzgados de paz en Buenos Aires, 1830-1852. Desarrollo Económico, 37 (146), 241262.

Galimberti, V. (2014). Autoridades locales y elecciones en la frontera norte bonaerense (1815-1828). En D. Barriera y R. Fradkin (Eds.), Gobierno, justicias y milicias: la frontera entre Buenos Aires y Santa Fe (1720-1830). Editorial de la Universidad de La Plata.

Galimberti, V. (2021). La participación electoral en Buenos Aires: una aproximación cuantitativa, 1815-1862, Anuario IEHS, 35 (2).

Gelman, J. (2000). Crisis y reconstrucción del orden en la campaña de Buenos Aires. Estado y sociedad en la primera mitad del siglo XIX. Boletín del Instituto de Historia Argentina y Americana "Dr. Emilio Ravignani", Tercera serie (21), 1er. semestre, 7-31.

Halperín Donghi, T. (1982). Una nación para el desierto argentino. Centro Editor de América Latina.

Ibarguren Aguirre, C. (2016). Patricio Lynch. Genealogía Familiar. Revista Trimestral de Genealogía, Historia y Ciencias Afines, Año III (9). Temperley Comercio y Servicio S.L. 
Kozul, P. (2018). Los municipios decimonónicos en Entre Ríos. La construcción de jurisdicciones locales en la consolidación del estado provincial, 1872-1883. En: S. Tedeschi y G. Pressel (Comps.), IX Reunión Anual Comité Académico de "Historia y fronteras" de la Asociación de Universidades Grupo Montevideo (AUGM), UNL-FHUC.

Lanteri, S. y Santilli, D. (2010). Consagrando a los ciudadanos. Procesos electorales comparados en la campaña de Buenos Aires durante la primera mitad del siglo XIX. Revista de Indias, LXX (249), 551-582.

Lettieri, A. (2003). La guerra de las representaciones: la revolución de septiembre de 1852 y el imaginario social porteño. En H. Sabato y A. Lettieri (Comps.), La vida política en la Argentina del siglo XIX. Armas, votos y voces. Fondo de Cultura Económica.

Libro de Acuerdos Municipalidad de Baradero 1856-1862. Archivo Histórico Judicial de la Provincia de Buenos Aires.

Macías, F. (2019). Reflexiones en torno a la guerra. Tucumán y el Norte Argentino en el siglo XIX. Investigaciones y Ensayos, ANH, (67), 55-80.

Martiren, J. L. (2010). Extranjeros y poder municipal en la campaña bonaerense: Alcances e influencias en el control del poder municipal en la segunda mitad del siglo XIX. Memoria Académica, Trabajos y Comunicaciones (36), 71-91.

Mateo J. (2013). La sociedad: población, estructura social y migraciones. En M. Ternavasio (Dir.), Historia de la provincia de Buenos Aires: de la organización federal a la federalización de Buenos Aires: 1821-1880, Edhasa; Gonnet; UNIPE: Editorial Universitaria.

Miguez, E. (2018). Bartolomé Mitre: entre la nación y la historia. Edhasa.

Morelli, F. (2007). Orígenes y valores del municipalismo iberoamericano. Araucaria: Revista Iberoamericana de filosofía, política y humanidades, (18), 116-129.

Newland, C. (1992). Buenos Aires no es pampa: la educación elemental porteña, 18201860. Grupo Editor Latinoamericano.

Primer Censo de la República Argentina verificado en los días 15, 16 y 17 de septiembre de 1869. Buenos Aires, Imprenta del Porvenir, 1872.

Ratto, S. (2015). Redes políticas en la frontera bonaerense 1836-1873: crónica de un final anunciado. Universidad Nacional de Quilmes.

Recopilación de leyes y decretos promulgados en Buenos Aires desde enero de 1841 hasta la fecha, Buenos Aires, Imprenta de Mayo, 1858.

Registro Oficial del Gobierno del Estado de Buenos Aires, Buenos Aires, Imprenta de Mayo, años varios. 
Sabato, H. (1998). La política en las calles. Entre el voto y la movilización. Buenos Aires, 1862-1880. Sudamericana.

Sabato, H. (2008). Buenos Aires en armas. La revolución de 1880. Siglo XXI Editores.

Salaberry, I. (2009). Brazos Poderosos. Inmigración, agricultura y municipio en el Estado de Buenos-Ayres: creación de la Colonia Suiza del Baradero. De los Cuatro Vientos.

Sarmiento, D. F. (1856). "Vida municipal. Municipalidad y escuelas", 05-04-1856, Obras Completas T. XXVI.

Scobie, J. (1964), La lucha por la consolidación de la nacionalidad argentina [18521862]. Hachette.

Sonzogni, E. y Bonaudo, M. (1997). Las finanzas municipales: una asignatura pendiente en la historiografía argentina del siglo XIX. El caso de Santa Fe (18531890), América Latina en la Historia Económica, (7), 27-34.

Ternavasio, M. (1991). Municipio y política. Un vínculo histórico conflictivo. (Tesis de Maestría inédita). FLACSO.

Ternavasio, M. (1995). Nuevo régimen representativo y expansión de la frontera política. Las elecciones en el estado de Buenos Aires: 1820-1840. En A. Annino (Coord.), Historia de las elecciones en Iberoamérica, siglo XIX. De la formación del espacio político nacional. FCE.

Ternavasio, M. (1999). Hacia un régimen de unanimidad. Política y elecciones en Buenos Aires, 1828-1850. En H. Sabato (Comp.), Ciudadanía política y formación de las naciones. Perspectivas históricas de América Latina, (pp. 119-141). Fondo de Cultura Económica.

Ternavasio, M. (2015). La revolución del voto. Política y elecciones en Buenos Aires, 1810-1852. Siglo Veintiuno Editores.

Yangilevich, M. (2018). Prefecturas, comisarías de campaña y construcción estatal en la Provincia de Buenos Aires (Argentina) a mediados del siglo XIX. Revista Secuencia, (108), septiembre-diciembre.

Zubizarreta, I. (2018). Politización y transformaciones sociales en los pueblos de la campaña del Estado de Buenos Aires, 1852-1861. Revista Diálogos 19 (2), Juliodiciembre, 101-125. 